\section{(2) OPEN ACCESS}

\title{
Occupational exposure to dust and to fumes, work as a welder and invasive pneumococcal disease risk
}

 \\ Ingemar Qvarfordt, ${ }_{1}^{5}$ Olov Aspevall, ${ }_{1}^{6}$ Anna Dahlman-Hoglund, ${ }^{7}$ Linus Schioler (i) ${ }^{1}$
}

\begin{abstract}
- Additional material is published online only. To view please visit the journal online (http://dx.doi.org/10.1136/ oemed-2019-106175).
\end{abstract}

For numbered affiliations see end of article.

\section{Correspondence to} Professor Kjell Torén, Occupational and Environmental medicine, School of Public Health and Community

Medicine, Sahlgrenska Academy, University of Gothenburg, Gothenburg, Sweden; kjell.toren@amm.gu.se

Received 26 August 2019 Revised 31 October 2019 Accepted 21 November 2019 Published Online First 17 December 2019

\section{Check for updates}

(C) Author(s) (or their employer(s)) 2020. Re-use permitted under CC BY-NC. No commercial re-use. See rights and permissions. Published by BMJ.

\footnotetext{
To cite: Torén $\mathrm{K}$,

Blanc PD, Naidoo RN,

et al. Occup Environ Med

2020;77:57-63.
}

\section{ABSTRACT}

Objectives Occupational exposures to metal fumes have been associated with increased pneumonia risk, but the risk of invasive pneumococcal disease (IPD) has not been characterised previously.

Methods We studied 4438 cases aged 20-65 from a Swedish registry of invasive infection caused by Streptococcus pneumoniae. The case index date was the date the infection was diagnosed. Six controls for each case, matched for gender, age and region of residency, were selected from the Swedish population registry. Each control was assigned the index date of their corresponding case to define the study observation period. We linked cases and controls to the Swedish registries for socioeconomic status (SES), occupational history and hospital discharge. We applied a jobexposure matrix to characterise occupational exposures. We used conditional logistic analyses, adjusted for comorbidities and SES, to estimate the OR of IPD and the subgroup pneumonia-IPD, associated with selected occupations and exposures in the year preceding the index date.

Results Welders manifested increased risk of IPD (OR 2.99, 95\% Cl 2.09 to 4.30). Occupational exposures to fumes and silica dust were associated with elevated odds of IPD (OR 1.11, 95\% CI 1.01 to 1.21 and OR 1.33, $95 \% \mathrm{CI} 1.11$ to 1.58 , respectively). Risk associated with IPD with pneumonia followed a similar pattern with the highest occupational odds observed among welders and among silica dust exposed.

Conclusion Work specifically as a welder, but also occupational exposures more broadly, increase the odds for IPD. Welders, and potentially others with relevant exposures, should be offered pneumococcal vaccination.

\section{INTRODUCTION}

In 1994, a British study reported increased risk of fatal lobar pneumonia among welders. ${ }^{1}$ Increased mortality risk was restricted to men of working age; in the over 65 age group, there was no increased mortality. In additional studies, the same research group later confirmed increased risk of lobar pneumonia in welders, as well as observing a similar phenomenon in other occupations with possible exposure to metal fumes, such as foundry workers. The observed risk was highest following fume exposure that had occurred in the year preceding disease onset. ${ }^{2}$ A large cohort study of construction workers in Sweden also found an increased risk of lobar pneumonia in men of working age occupationally exposed to metal fumes or inorganic

\section{Key messages}

What is already known about this subject?

- Occupational exposures to metal fumes have been associated with increased pneumonia risk.

What are the new findings?

- This population-based case-control study provides evidence that work as a welder as well as occupational exposure to fumes more broadly and to silica dust confer increased risk for invasive pneumococcal disease, supporting and clarifying relationships observed in relation to pneumonia generally but not defined previously by invasive pneumococcal disease.

How might this impact on policy or clinical practice in the foreseeable future?

- Workers exposed to fumes, especially metal fumes, may be at increased risk for invasive pneumococcal disease. Strategies for risk reduction should be considered, including targeted pneumococcal vaccination for workers being exposed.

dust. ${ }^{4}$ A recent comprehensive review summarised additional studies identifying an increased risk of pneumonia (although not specified as lobar) among workers occupationally exposed to 'inorganic dusts' which may include metal particulates. ${ }^{5}$

Streptococcus pneumoniae, an encapsulated Gram-positive diplococcus, causes a wide spectrum of human disease, ranging from sinusitis and otitis media to more severe pathologies, in particular lobar pneumonia. ${ }^{7}$ Lobar pneumonia and other serious infections from this organism typically are characterised by invasive pneumococcal disease (IPD), defined as pneumococcal bacterial growth cultured from a normally sterile site such as blood, cerebrospinal fluid or joint fluid. Exposure to irritants such as direct and secondhand tobacco smoke independently increase the risk of pneumonia caused by $S$. pneumoniae, as do ethanol abuse and certain comorbidities. ${ }^{8}$

Whether occupational exposure to metal fumes or fumes more broadly defined increase the risk for IPD warrants further investigation. A single study from Alberta, Canada, addressed this question using a provincial disease registry comprising 863 working-age patients with IPD. ${ }^{9}$ Using census data to define population at risk, the incidence of 
IPD was assessed for four occupations: welders, farmers, electricians and daycare workers. In that analysis, which was unadjusted, only welders manifested statistically significant increased odds of IPD (OR 2.7, 95\% CI 1.7 to 4.2). In a descriptive study of working patients with IPD using the same registry, construction workers were over-represented compared with the general Alberta population, $25.3 \%(n=147)$ versus $11.0 \%$. Of note, welders accounted for $36 \%$ of the construction workers. ${ }^{10}$

We hypothesised that welders, as well as other occupations with potential metal fume exposures, are at increased risk of IPD, especially IPD with underlying pneumonia. Second, we also hypothesised that occupational exposures to fumes more broadly defined and inorganic dust may increase the risk of IPD.

\section{MATERIALS AND METHODS \\ Ascertainment of cases}

Since 1 July 2004, IPD cases have been included in the mandatory reporting scheme of communicable diseases in Sweden. This mandatory reporting applies to laboratories which reports to a central database, SmiNet. The reports from the laboratories are generated automatically, based on types of specimens (normally sterile specimens, eg, blood) and isolation of pneumococci, and sent automatically to the central database. The mandatory inclusion of all laboratories and the automated reporting of data ensures nearly complete coverage of incident cases in the Swedish population.

We defined cases with IPD as those reported through the Swedish reporting system as detailed above. Results from urine antigen tests were not considered to define a case. Case eligibility was limited to those aged 20 to 65 years (ie, of working age). We limited this analysis to cases reported from 1 July 2006 through 31 December 2014. We extracted data for Swedish personal identity number, type of sample (blood, joint fluid etc) and the date (index date) when the sample was obtained.

\section{Ascertainment of controls}

Controls without IPD were randomly selected from the Swedish National Population Registry. We selected six living controls for each case, matched for gender, age (case year of birth) and region of residency (four urban areas and three rural areas). We assigned each control the index date of their corresponding case to define the study observation period.

\section{Matching with national registries}

We used the Swedish National Hospital Discharge Registry to identify the following comorbid conditions based on ICD-10 coding present at any time within the 5 years preceding the index date: chronic obstructive pulmonary disease (COPD) (J43-J44), asthma (J45) and diabetes mellitus (E10-E14). We also used this registry to identify hospitalisation for any pneumonia (J10-J18), including any hospital stay that at least included the index date \pm 7 days.

We extracted information from the Swedish national socioeconomic database (Longitudinal integration database for health insurance and labour market studies, LISA) on the highest educational level obtained, categorised as pre-high school (up to 9 years), high school or university examination. We used this as a surrogate for socioeconomic status (SES). From LISA, we also obtained information about the occupation held as of 1 November of the year preceding the index date for both cases and controls.

We defined ethanol abuse as either hospitalisation for alcohol abuse disorder (ICD-10 F10) or prescriptions dispensed for drugs used in the treatment of alcohol dependence (from the Swedish Prescribed Drug Registry) at any time within 5 years before index date. From the same registry, we also extracted information about pneumococcal vaccinations at any time within 5 years before index date. The exact drug code that we used is listed in online supplementary material table A.

\section{Classification of occupational exposures}

The occupation the year preceding the index date, considered as the current occupation, was classified at four-digit level according to ISCO-88. ${ }^{11}$ To assess occupational exposures, we both considered specific occupations of inherent risk of metal fume exposure and used a previously published Nordic job-exposure matrix, $\mathrm{N}$-JEM, to assign exposure risks more broadly. ${ }^{12}$ This JEM was originally developed and validated based on information from large Swedish population studies in randomly selected subjects aged 25 to 74 years. $^{12}$

For this analysis, all occupations in the JEM were re-assessed by two senior occupational hygienists as being occupationally exposed or not to fumes, inorganic dust including silica dust, silica dust, vapour and gas, and organic dust. Fumes were defined as smoke from various combustion processes, such as welding, fires and from tobacco smoke. Vapour and gas was defined as substances in aerosol or gas phase. In the JEM, occupations can be classified as exposed to more than one of these categories of agents. The exposure assessments for the JEM were further reviewed by three specialists in occupational medicine and adjudicated until consensus was achieved. An exposed occupation was defined based on the assumption that at least half of the subjects with these specific codes should have a strong probability of being exposed to the critical agents. In addition, all exposures originally were graded into low and high (or no exposure). All expert assessments were carried out blind to case status.

In addition to the separate categories, we also merged all exposures into an 'any exposure' versus none as another exposure metric. Occupations (ISCO codes) classified as high exposed in each subgroup in the JEM are presented in online supplementary material tables B-F.

\section{Statistical methods}

The unique personal identity number given to all Swedish citizens allowed for linkage among all registries used in this study. Based on these linkages, we identified a 'pneumonia' subset of IPD cases with a hospitalisation or death with any ICD-10 bacterial pneumonia code (J10 through J18). Hence, two main disease outcomes were defined: IPD and, as a subset of the former, IPD with pneumonia. In an additional analysis, we also analysed IPD without pneumonia as an outcome.

We used conditional logistic regression to calculate OR of IPD or IPD with pneumonia associated with selected occupations and also based on JEM-defined exposures across all occupations. We selected a priori four occupations that we considered characterised by exposure to metal fumes: welders, foundry workers, steel mill workers and blacksmiths. We also merged these four occupations to the group categorised as metalworkers. We initially performed unadjusted models (although with referents matched for age, gender and region of residence, as noted). We performed additional analyses including the following covariates: comorbid conditions (COPD, asthma and diabetes, based on hospitalisation within 5 years of the index date), SES (educational level defined dichotomously as university graduate vs less education) and ethanol abuse. All models with multiple JEM classifications 
Table 1 Characteristics of cases with invasive pneumococcal disease (IPD) and matched controls from the general population of Sweden

\begin{tabular}{|c|c|c|c|c|}
\hline & All IPD $(n=4438)$ & $\begin{array}{l}\text { Controls } \\
(n=21080)\end{array}$ & $\begin{array}{l}\text { IPD with pneumonia } \\
(\mathrm{n}=3143)\end{array}$ & $\begin{array}{l}\text { Controls } \\
(n=14979)\end{array}$ \\
\hline Men & $52.9 \%$ & $53.1 \%$ & $54.0 \%$ & $54.3 \%$ \\
\hline Age, years (SD) & $51.5(11.5)$ & $50.9(11.2)$ & $51.2(11.5)$ & $50.7(11.3)$ \\
\hline Completed university & $31.9 \%$ & $37.2 \%$ & $31.0 \%$ & $37.3 \%$ \\
\hline Chronic obstructive pulmonary disease & $4.8 \%$ & $0.5 \%$ & $5.5 \%$ & $0.4 \%$ \\
\hline Bronchial asthma & $6.8 \%$ & $2.0 \%$ & $7.5 \%$ & $2.0 \%$ \\
\hline Diabetes mellitus & $9.8 \%$ & $1.5 \%$ & $10.0 \%$ & $1.5 \%$ \\
\hline Ethanol abuse & $3.7 \%$ & $0.9 \%$ & $3.8 \%$ & $1.0 \%$ \\
\hline Pneumococcal vaccination & $0.2 \%$ & $<0.1 \%$ & $0.1 \%$ & $<0.1 \%$ \\
\hline \multicolumn{5}{|l|}{ Occupations } \\
\hline Welders and flame-cutters & $1.1 \%$ & $0.4 \%$ & $1.4 \%$ & $0.5 \%$ \\
\hline Foundry workers & $0.1 \%$ & $<0.1 \%$ & $<0.1 \%$ & $<0.1 \%$ \\
\hline Steel mill workers & $0.4 \%$ & $0.4 \%$ & $0.5 \%$ & $0.3 \%$ \\
\hline Blacksmiths & $0.4 \%$ & $0.2 \%$ & $0.5 \%$ & $0.2 \%$ \\
\hline All metalworkers* & $2.1 \%$ & $1.0 \%$ & $2.4 \%$ & $1.1 \%$ \\
\hline \multicolumn{5}{|c|}{ Occupational exposures based on job-exposure matrix } \\
\hline Fumes & $18.8 \%$ & $16.6 \%$ & $19.4 \%$ & $16.5 \%$ \\
\hline All inorganic dust & $23.1 \%$ & $19.7 \%$ & $23.4 \%$ & $19.8 \%$ \\
\hline Silica dust & $4.7 \%$ & $3.2 \%$ & $4.6 \%$ & $3.2 \%$ \\
\hline Vapours and gases & $21.7 \%$ & $20.1 \%$ & $22.0 \%$ & $20.1 \%$ \\
\hline Organic dust & $8.2 \%$ & $8.3 \%$ & $7.8 \%$ & $8.4 \%$ \\
\hline Any exposure $†$ & $39.8 \%$ & $36.0 \%$ & $40.4 \%$ & $36.2 \%$ \\
\hline
\end{tabular}

*A merger of welders (and flame-cutters), foundry workers, steel mill workers and blacksmiths.

tAll five job-exposure matrix categories combined.

exposures were adjusted for the all other exposures. The models including the JEM-based 'Any exposure' category were not adjusted for other occupational exposures. We repeated all main models in gender-stratified analyses. We also performed additional JEM-based analyses excluding those workers in the occupational category 'metalworkers'. We also performed analyses restricted to persons $>50$ years up to 65 years of age.

We calculated the attributable fraction (AF) within selected occupations and categories of JEM exposures as OR-1/OR. ${ }^{13}$ CIs (95\%) were calculated using exact methods. All analyses were performed using SAS V.9.4 M5 (SAS Institute, Cary, NC, USA).

\section{RESULTS}

We initially identified 6565 IPD cases and 39390 matched controls. We excluded cases who did not have a current occupation and controls matched to an excluded case or a control who also had no current occupation. After these exclusions, there were 4438 eligible IPD cases and 21080 matched referents. Among the IPD cases, 3143 (70.8\%) were diagnosed with concomitant pneumonia while 1295 (29.2\%) did not have this concurrent diagnosis. Demographics, comorbid conditions, occupational exposures and pneumococcal vaccination rates (notably low in both cases and controls) are shown in table 1.

Table 2 shows the estimated ORs for IPD and IPD with pneumonia associated with the a priori selected occupations involving metal fume exposure. In adjusted models, welders (including flame-cutters) manifested increased odds of both IPD (OR $2.99,95 \%$ CI 2.09 to 4.30 ) and IPD with pneumonia (OR 3.28, $95 \%$ CI 2.22 to 4.84$)$. Two of the specific occupations were associated with elevated point estimates of IPD and IPD with pneumonia tested, but only for blacksmiths did the 95\% CI exclude 1.0. When combined together, metal fume-exposed occupations were associated with more than doubled odds for both IPD and
IPD with pneumonia (OR 2.12, 95\% CI 1.58 to 2.83 and OR $2.48,95 \% \mathrm{CI} 1.80$ to 3.43 , respectively). The AF of IPD among welders was 0.67 (95\% CI 0.52 to 0.77 ), and for IPD with pneumonia it was $0.70(95 \% \mathrm{CI} 0.55$ to 0.79$)$. The $\mathrm{AF}$ among all four metalworking trades combined was 0.53 (95\% CI 0.37 to 0.65 ), and for IPD with pneumonia it was 0.60 (95\% CI 0.44 to 0.71 ).

Table 2 Logistic regression models of risks of invasive pneumococcal disease (IPD) and IPD with pneumonia in relation to work as welder, foundry worker, steel mill worker or blacksmith the year preceding the index date (onset of IPD)

\begin{tabular}{|c|c|c|c|c|}
\hline \multirow[b]{2}{*}{ Occupation } & \multicolumn{2}{|c|}{ All IPD $(n=4438)$} & \multicolumn{2}{|c|}{$\begin{array}{l}\text { IPD with pneumonia } \\
(\mathrm{n}=3143)\end{array}$} \\
\hline & $\mathrm{OR}$ & $95 \%$ & OR & $95 \%$ \\
\hline \multicolumn{5}{|l|}{ Welder $(n=136)$} \\
\hline Simple model* & 2.8 & 1.97 to 3.99 & 3.09 & 2.12 to 4.51 \\
\hline Adjusted model $t$ & 2.99 & 2.09 to 4.30 & 3.28 & 2.22 to 4.84 \\
\hline Foundry worker $(n=6) \ddagger$ & NA & NA & NA & NA \\
\hline \multicolumn{5}{|l|}{ Steel mill worker $(\mathrm{n}=98)$} \\
\hline Simple model* & 1.16 & 0.70 to 1.92 & 1.44 & 0.80 to 2.57 \\
\hline Adjusted model $\dagger$ & 1.1 & 0.65 to 1.86 & 1.43 & 0.78 to 2.60 \\
\hline \multicolumn{5}{|l|}{ Blacksmiths ( $n=69)$} \\
\hline Simple model ${ }^{*}$ & 1.93 & 1.14 to 3.27 & 2.12 & 1.16 to 3.87 \\
\hline Adjusted modelt & 1.96 & 1.13 to 3.39 & 2.22 & 1.89 to 4.16 \\
\hline \multicolumn{5}{|l|}{ All metalworkers $(n=309)$} \\
\hline Simple model* & 2.1 & 1.58 to 2.77 & 2.41 & 1.76 to 3.29 \\
\hline Adjusted modelt & 2.12 & 1.58 to 2.83 & 2.48 & 1.80 to 3.43 \\
\hline
\end{tabular}

${ }^{*}$ Matched for gender, age and place of residency.

$\dagger 1+$ adjusted for educational level (university graduate vs other), chronic obstructive pulmonary disease, asthma, diabetes and ethanol abuse.

$\ddagger$ Not analysed due to too few cases; three foundry workers and three controls. NA, not applicable. 
Table 3 Logistic regression models of invasive pneumococcal disease (IPD) risk and IPD with pneumonia in relation to occupational exposure to vapours and gases, inorganic dust, silica dust, fumes, silica dust and organic dust during the year preceding the index date (onset of IPD)

\begin{tabular}{|c|c|c|c|c|c|c|}
\hline \multirow[b]{3}{*}{ Occupational exposures } & \multicolumn{6}{|l|}{ IPD } \\
\hline & \multicolumn{3}{|c|}{$\begin{array}{l}\text { All IPD } \\
(n=4438)\end{array}$} & \multicolumn{3}{|c|}{$\begin{array}{l}\text { IPD with pneumonia } \\
(n=3143)\end{array}$} \\
\hline & $\mathrm{N}$ & OR & $95 \%$ & $\mathrm{~N}$ & OR & $95 \%$ \\
\hline \multicolumn{7}{|l|}{ Fumes } \\
\hline Any exposure & 836 & 1.11 & 1.01 to 1.21 & 611 & 1.17 & 1.06 to 1.30 \\
\hline Low* & 780 & 1.07 & 0.97 to 1.17 & 560 & 1.1 & 0.98 to 1.23 \\
\hline High* $^{*}$ & 56 & 2.4 & 1.72 to 3.36 & 51 & 2.71 & 1.89 to 3.89 \\
\hline \multicolumn{7}{|l|}{ Inorganic dust } \\
\hline Any exposure* & 1024 & 1.1 & 0.99 to 1.21 & 735 & 1.26 & 1.14 to 1.39 \\
\hline Low $^{*}$ & 990 & 1.09 & 0.98 to 1.20 & 710 & 1.08 & 0.96 to 1.22 \\
\hline High* $^{*}$ & 34 & 1.46 & 0.96 to 2.21 & 25 & 1.51 & 0.93 to 2.44 \\
\hline \multicolumn{7}{|l|}{ Silica dust } \\
\hline Any exposure* & 208 & 1.33 & 1.11 to 1.58 & 144 & 1.33 & 1.08 to 1.64 \\
\hline Low $^{*}$ & 186 & 1.3 & 1.08 to 1.56 & 128 & 1.32 & 1.05 to 1.65 \\
\hline High* $^{*}$ & 22 & 1.55 & 0.93 to 2.57 & 16 & 1.41 & 0.78 to 2.54 \\
\hline \multicolumn{7}{|l|}{ Vapours and gases } \\
\hline Any exposure* & 963 & 0.96 & 0.87 to 1.06 & 693 & 1.07 & 0.97 to 1.18 \\
\hline Low* & 886 & 0.92 & 0.83 to 1.02 & 628 & 0.91 & 0.80 to 1.03 \\
\hline High* & 77 & 1.93 & 1.44 to 2.57 & 65 & 2.19 & 1.59 to 3.03 \\
\hline \multicolumn{7}{|l|}{ Organic dust } \\
\hline Any exposure* & 362 & 0.93 & 0.81 to 1.05 & 246 & 0.92 & 0.80 to 1.06 \\
\hline Low* & 347 & 0.92 & 0.81 to 1.05 & 237 & 0.85 & 0.73 to 1.00 \\
\hline High* $^{*}$ & 15 & 1.12 & 0.60 to 2.09 & 9 & 1.02 & 0.47 to 2.21 \\
\hline Any exposuret & 1765 & 1.09 & 1.01 to 1.18 & 1269 & 1.08 & 0.99 to 1.19 \\
\hline
\end{tabular}

The exposure is defined by job-exposure matrix.

*Matched for gender, age and place of residency, and adjusted for educational level, ethanol abuse, and diagnoses of chronic obstructive pulmonary disease (COPD), asthma and diabetes and any other occupational exposures.

tMatched for gender, age and place of residency, and adjusted for educational level, ethanol abuse, and diagnoses of COPD, asthma and diabetes.

Occupational exposure to fumes defined more broadly by JEM (table 3) was associated with increased odds of IPD (OR $1.11,95 \%$ CI 1.01 to 1.21 ) and for IPD with pneumonia (OR $1.17,95 \%$ CI 1.06 to 1.30 ). Moreover, fume also demonstrated a step-up in effect, with high JEM exposure associated with a more than doubling of the odds for IPD and IPD with pneumonia (OR 2.40, 95\% CI 1.72 to 3.36 and OR 2.71, 95\% CI 1.89 to 3.89 , respectively).
Only one other JEM category of exposure, that of silica, exhibited a similar pattern of statistically increased risk of IPD and IPD with pneumonia and a step-up in statistically significant risk with high exposure (table 3). Merging all JEM-defined occupational exposures together into an 'any exposure' category yielded minimally increased odds for both IPD (OR 1.09, $95 \%$ CI 1.01 to 1.37 ) and for IPD with pneumonia (OR 1.08, $95 \%$ CI 0.99 to 1.18$)$.

Table 4 Logistic regression models of invasive pneumococcal disease (IPD) risk among men and women in relation to occupational exposure to vapours and gases, inorganic dust, silica dust, fumes, silica dust and organic dust during the year preceding the index date (onset of IPD)

\begin{tabular}{|c|c|c|c|c|c|c|c|c|}
\hline \multirow[b]{4}{*}{ Occupational exposures } & \multicolumn{8}{|l|}{ IPD } \\
\hline & \multicolumn{4}{|c|}{ All IPD $(n=4438)$} & \multicolumn{4}{|c|}{ IPD with pneumonia $(n=3143)$} \\
\hline & \multicolumn{2}{|c|}{ Men $(n=2347)$} & \multicolumn{2}{|c|}{ Women $(n=2091)$} & \multicolumn{2}{|c|}{ Men $(n=1698)$} & \multicolumn{2}{|c|}{ Women $(n=1445)$} \\
\hline & OR & $95 \%$ & OR & $95 \%$ & OR & $95 \%$ & OR & $95 \%$ \\
\hline Fumes & $\begin{array}{l}1.16 \\
(n=465)\end{array}$ & 1.03 to 1.31 & $\begin{array}{l}1.08 \\
(n=371)\end{array}$ & 0.93 to 1.25 & $\begin{array}{l}1.22 \\
(n=345)\end{array}$ & 1.06 to 1.41 & $\begin{array}{l}1.09 \\
(n=266)\end{array}$ & 0.91 to 1.30 \\
\hline Inorganic dust & $\begin{array}{l}1.13 \\
(n=794)\end{array}$ & 1.00 to 1.27 & $\begin{array}{l}0.98 \\
(n=230)\end{array}$ & 0.81 to 1.19 & $\begin{array}{l}1.16 \\
(n=575)\end{array}$ & 1.00 to 1.33 & $\begin{array}{l}0.92 \\
(n=160)\end{array}$ & 0.72 to 1.16 \\
\hline Silica dust & $\begin{array}{l}1.33 \\
(n=174)\end{array}$ & 1.10 to 1.61 & $\begin{array}{l}1.27 \\
(n=34)\end{array}$ & 0.81 to 2.00 & $\begin{array}{l}1.33 \\
(n=121)\end{array}$ & 1.06 to 1.67 & $\begin{array}{l}1.3 \\
(n=23)\end{array}$ & 0.73 to 2.32 \\
\hline Vapours and gases & $\begin{array}{l}0.99 \\
(n=660)\end{array}$ & 0.87 to 1.12 & $\begin{array}{l}0.91 \\
(\mathrm{n}=303)\end{array}$ & 0.76 to 1.08 & $\begin{array}{l}0.99 \\
(n=476)\end{array}$ & 0.85 to 1.14 & $\begin{array}{l}0.91 \\
(n=217)\end{array}$ & 0.74 to 1.12 \\
\hline Organic dust & $\begin{array}{l}0.92 \\
(n=298)\end{array}$ & 0.80 to 1.07 & $\begin{array}{l}0.93 \\
(n=64)\end{array}$ & 0.70 to 1.24 & $\begin{array}{l}0.86 \\
(n=204)\end{array}$ & 0.72 to 1.02 & $\begin{array}{l}0.88 \\
(n=42)\end{array}$ & 0.62 to 1.25 \\
\hline
\end{tabular}

The exposure is defined by job-exposure matrix. The models are matched for age and residency and adjusted for educational level, ethanol abuse, and diagnoses of chronic obstructive pulmonary disease, asthma and diabetes and any other occupational exposures. 
Table 5 Logistic regression models for invasive pneumococcal disease (IPD) risk and IPD with pneumonia in relation to occupation and to occupational exposure defined by job-exposure matrix restricted to cases and controls 50-65 years of age

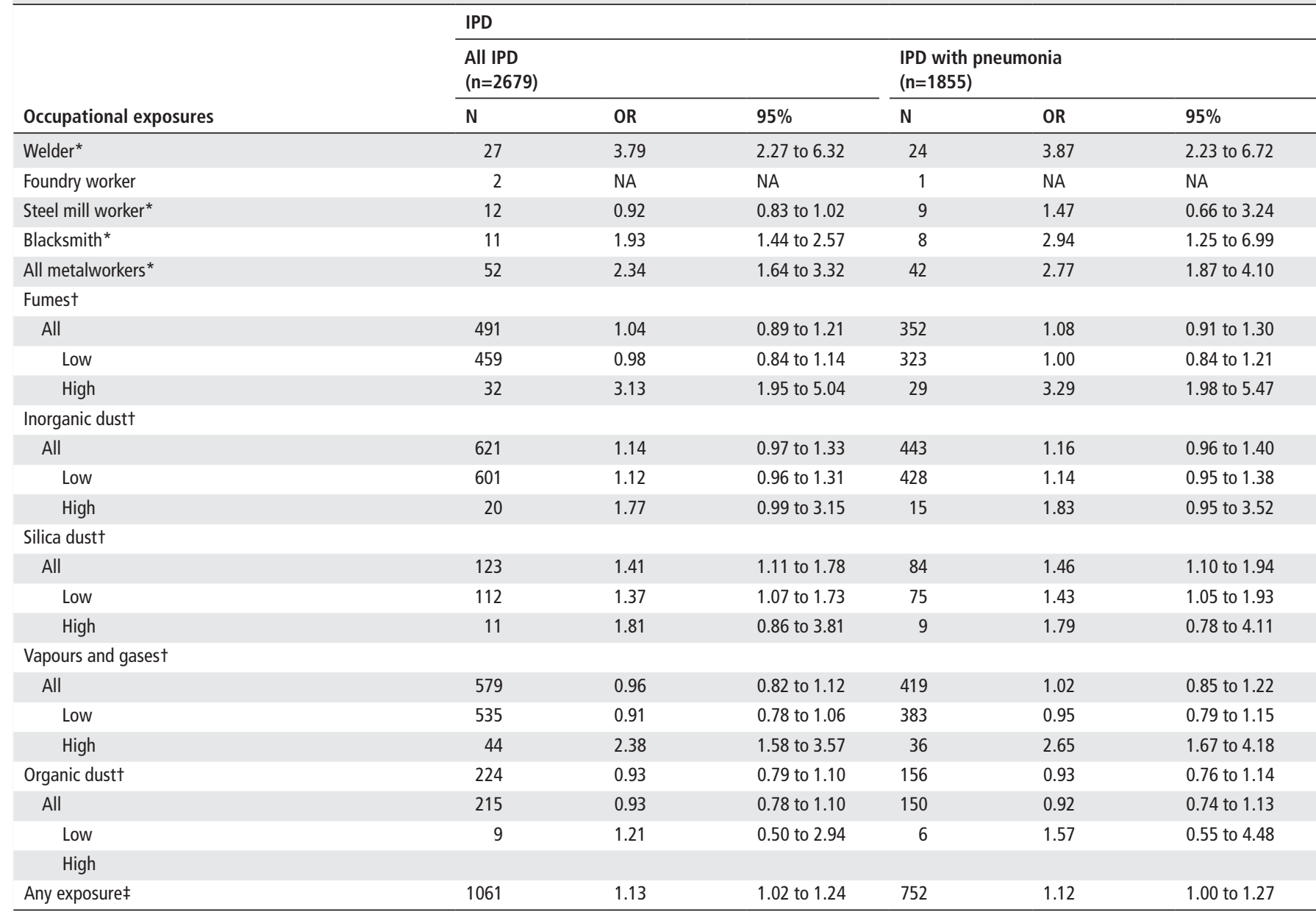

* Matched for gender, age and place of residency and adjusted for educational level, chronic obstructive pulmonary disease (COPD), asthma, diabetes and ethanol abuse.

tMatched for gender, age and place of residency, and adjusted for educational level, ethanol abuse, and diagnoses of COPD, asthma and diabetes and other occupational exposures.

¥Matched for gender, age and place of residency, and adjusted for educational level, ethanol abuse, and diagnosis of COPD, asthma and diabetes. NA, not applicable.

Stratified by gender, exposure to fumes, inorganic dust and silica remained statistically associated with IPD and IPD with pneumonia among men, while the risk was attenuated and no longer statistically significant among women (table 4).

For IPD without pneumonia $(n=1295)$, there was no clear relation of exposure to fumes or for any other of the JEMbased exposure categories (online supplementary material table G).

We also performed an additional analysis excluding all metalworkers (online supplementary material table $\mathrm{H}$ ). In that analysis, occupational exposure to fumes was no longer statistically associated with IPD or IPD with pneumonia. Occupational exposure to silica dust remained associated with increased risk for IPD (OR 1.35, 95\% CI 1.12 to 1.61) and for IPD with pneumonia (OR 1.33, 95\% CI 1.07 to 1.66 ).

When restricting the analyses to persons older than 50 years, the results were similar, as compared with the results from the whole study population, although some risk estimates were somewhat higher (table 5). Welders (including flame-cutters) showed increased odds of both IPD (OR 3.79, 95\% CI 2.22 to 6.32 ) and IPD with pneumonia (OR $3.87,95 \%$ CI 2.23 to 6.72).

\section{DISCUSSION}

This case-control study provides new and powerful populationbased evidence supporting the contention that occupational exposure to metal fumes defined by selected occupations is a potent risk factor for pneumonia. By defining this as a microbiologically confirmed severe disease, either as IPD or IPD with pneumonia, our study also sharpens the focus of this association. The estimated odds of disease take into account age, sex and geographical matching and are robust after adjustment for comorbid conditions, including airway disease and ethanolism. These findings extend previous observations by showing that severe infection, defined by IPD rather than simply broadly characterised community-acquired pneumonia, is an outcome of concern. We also found elevated odds of IPD associated with other categories of JEM-defined exposures beyond fumes, especially exposure to silica dust, although less consistently so, suggesting that other inhalants also may be potential risk factors for pneumococcal infection in working-age adults.

A major strength of our study is that we have been able to use national registry data with broad capture to assess the outcomes of interest: IPD and IPD with pneumonia. The registry we used provides a highly valid measure of disease, although 
we acknowledge that all cases of IPD may not be captured. In general, Swedish patient registers have high quality in effective case detection and classification. ${ }^{14}$ Another strength of our study is that we also used random controls from the same national population. Furthermore, we were able to consider a number of key potential confounders using Swedish registry data. These include both level of education (as a proxy for SES) and comorbidities that may modify pneumonia risk. Comorbidities included ethanolism (using a composite variable comprising ICD-10 coded ethanol abuse disorder or use of drugs treating alcohol dependence, mainly disulfiram aversion therapy), diabetes, asthma and COPD. The latter is also a marker, in part, for cumulative cigarette smoking. A possible limit is the lack of data on immunocompromising conditions beyond diabetes. The prevalence of such conditions, however, is relatively low in the general population. ${ }^{15}$ Further, it is very unlikely that those with immunocompromise were more selectively employed in at-risk occupations rather than to have been among the controls. Although ascertainment bias is always a theoretical concern, as noted above, the registry source is likely to be reliable and with minimal ascertainment bias imparting substantive bias.

Another notable weakness of our analysis is the lack of direct data on smoking habits, in particular current tobacco use. Active current smoking has been associated with an increased risk for IPD, with as high as a fivefold increased risk among current smokers. ${ }^{816}$ In Sweden, the prevalence of current smoking in the age group 50 to 65 is approximately $17 \%,{ }^{17}$ making smoking a potential confounder sufficiently common to explain the associations that we observed, if compared with others, current smokers were substantially more likely than never-smokers to work in metal fume-exposed occupations. Of note, however, in addition to COPD as noted previously, we also adjusted for educational level which is known to be linked to smoking status in northern Europe, as well as in Sweden. ${ }^{18}$ Nonetheless, residual confounding due to smoking cannot be excluded.

The occupational exposures, as well, were based on registry data (ie, occupational titles) and formed basis for inferred exposure. Therefore, exposure was not assessed, case by case, either through interview or through industrial hygiene assessment of workplaces. Job titles were further transformed to capture exposure likelihood both by job categories that clearly entailed metalwork and through application of an established JEM. The JEM we used was based on exposure assessments from the 1980s and 1990s, and several experienced occupational hygienists were involved in the development of this JEM. ${ }^{12}$ We only considered occupational exposure based on employment the year before the disease onset. This was predicated on the assumption that recent exposure is more important than cumulative exposure as a risk factor for IPD. ${ }^{2}$ Hence, the study population was restricted to the age range 20 to 65 years of age. A limitation of the JEM, however, is that it does not have a category that is exclusive to metal fumes. To the extent that the JEM misclassifies exposure, it would likely bias towards the null and would not explain the associations that we did observe.

Our results strongly support the hypothesis that exposure to fumes, especially metal fumes, is associated with increased risk of pneumococcal infection. In the additional analysis, where all potentially metal fume-exposed occupations were excluded from the analysis, only exposure to silica dust remained significantly increased. This further supports that the increased risks for fumes and vapours and gases are driven by exposure to metal fumes. In addition to the other epidemiological evidence cited previously, ${ }^{1-4}$ other clinical data are also relevant to this question. A case series from Norway reported three lethal cases of pneumonia with septicaemia. ${ }^{19}$ Two of the cases were shipyard welders and the third was a helper in a workshop for heavy trucks, occasionally assisting welders. Nine cases (four confirmed and five probable) of invasive pneumococcal disease were described at a shipyard in Northern Ireland. ${ }^{20}$ All were men 20 to 50 years of age and isolation of S. pneumoniae serotypes 3 and 4 was confirmed. Three of them were welders and the others had occupations described as potentially involving exposure to welding fumes. A case series from Sweden reported four cases of pneumonia and confirmed isolation of $S$. pneumoniae. ${ }^{21}$ The workplace was a large construction site and two workers were grinding, one was an electrician and a fourth was a welder.

Beyond metal fumes, our JEM analysis suggests that exposure to silica dust, adjusted for other exposures and potential confounders, may be an independent risk factor for IPD, and especially IPD with pneumonia although the estimated odds for high exposure were not statistically significant. Previous studies have noted an increased risk of pneumonia among workers exposed to inorganic dust. ${ }^{42}$ We are not aware of any study specifically implicating silica dust as a risk factor for IPD or IPD with pneumonia.

The results also indicate that it is especially IPD with pneumonia that is the main outcome at risk, as IPD without pneumonia did not show any increased risk estimates. The mechanism for metal fumes and potentially other occupational inhalants to increase the risk of IPD and IPD with pneumonia is not established. Inhalation of metal fumes, inorganic and silica dust may suppress alveolar macrophages, causing impaired pulmonary clearance of pathogens and impaired host defence in the respiratory tract. ${ }^{23-25}$ It has also been shown that ultrafine particles present in welding fumes increase the adherence of $S$. pneumoniae to the respiratory epithelium. ${ }^{26}$ Iron particulates present in welding and other metal fumes may facilitate infections by acting as a virulence factor for certain siderophilic micro-organisms, especially $S$. pneumoniae. ${ }^{23} 26$

The seminal 1994 British publication was accompanied by an editorial concluding that lobar pneumonia should be classified as an occupational disease in welders. ${ }^{1}{ }^{27}$ We can now extend this statement to also include IPD, which also should be regarded as an occupational disease among welders. Given that the attributable fraction is greater than 0.5 among welders and, indeed, among all four of the metal fume-exposed occupations we considered, this means that in any such worker with IPD, it is more likely than not that the condition can be attributed to work-related exposure.

In Sweden, at the time of the present study, pneumococcal vaccination was recommended for all persons over 65 years, but only for certain other risk groups at a younger age. ${ }^{28}$ Our data (table 1) show that the prevalence of vaccination in the population we studied was very low. Importantly, the findings of this study support the suggestion that work as welder or in other occupations with heavy metal fume exposure may be an indication for pneumococcal vaccination. This intervention has been debated in the UK, but has not been instituted. ${ }^{29}$ The first line of prevention, however, has to be reduction of workplace exposure to welding fumes and other metal fumes, as well as gases and inorganic dusts.

In conclusion, we found that selected jobs involving metal fume exposure carried increased odds for invasive pneumococcal infection, as well as invasive pneumococcal infection with concomitant pneumonia. These results support interventions to reduce these exposures and to provide pneumococcal vaccination to such workers. 


\section{Author affiliations}

'Occupational and Environmental medicine, School of Public Health and Community Medicine, Sahlgrenska Academy, University of Gothenburg, Gothenburg, Sweden 2Department of Occupational and Environmental Health, University of KwaZuluNatal, Durban, South Africa

${ }^{3}$ Division of Occupational and Environmental Medicine, Department of Medicine, University of California, San Francisco, California, United States

${ }^{4}$ Section of Occupational Medicine, Respiratory Diseases and Toxicology University of Perugia, Perugia, Italy

${ }^{5}$ Department of Infection Prevention and Control, Sahlgrenska University Hospital, Gothenburg, Sweden

${ }^{6}$ Unit for Surveillance and Coordination, Public Health Agency, Solna, Stockholm, Sweden

${ }^{7}$ Department of Occupational and environmental medicine, Sahlgrenska University Hospital, Gothenburg, Sweden

Contributors KT designed the study, interpreted the data, wrote the first draft of the manuscript and is the guarantor of the manuscript. KT and LS have full access to the data and KT had the final responsibility to submit the manuscript. PDB, RNN, AD-H and NM interpreted the data and assisted in the drafting of the manuscript. AD-H was responsible for the job-exposure matrices. IQ and OA acquired the data and interpreted the data. $L S$ analysed the data, interpreted the data and assisted in the drafting of the manuscript. All authors approved the final version the manuscript.

Funding Swedish Heart and Lung Foundation, Swedish Council for Working Life, Health, and Welfare (FORTE) and by grants from the Swedish state under the agreement between the Swedish government and the county councils, the ALFagreement, 74570 .

Competing interests None declared.

Patient consent for publication Not required.

Ethics approval The Gothenburg Committee of Ethics approved the study (Dnr 729-16).

Provenance and peer review Not commissioned; externally peer reviewed.

Data availability statement Data may be obtained from a third party and are not publicly available.

Open access This is an open access article distributed in accordance with the Creative Commons Attribution Non Commercial (CC BY-NC 4.0) license, which permits others to distribute, remix, adapt, build upon this work non-commercially, and license their derivative works on different terms, provided the original work is properly cited, appropriate credit is given, any changes made indicated, and the use is non-commercial. See: http://creativecommons.org/licenses/by-nc/4.0/.

\section{ORCID iDs}

Kjell Torén http://orcid.org/0000-0001-8509-7603

Paul D Blanc http://orcid.org/0000-0001-9043-175X

Rajen N Naidoo http://orcid.org/0000-0002-2318-4004

Linus Schioler http://orcid.org/0000-0002-8395-9625

\section{REFERENCES}

1 Coggon D, Inskip H, Winter P, et al. Lobar pneumonia: an occupational disease in welders. Lancet 1994;344:41-3.

2 Palmer KT, Poole J, Ayres JG, et al. Exposure to metal fume and infectious pneumonia. Am J Epidemiol 2003;157:227-33.

3 Palmer KT, Cullinan P, Rice $S$, et al. Mortality from infectious pneumonia in metal workers: a comparison with deaths from asthma in occupations exposed to respiratory sensitisers. Thorax 2009;64:983-6.
4 Torén K, Qvarfordt I, Bergdahl IA, et al. Increased mortality from infectious pneumonia after occupational exposure to inorganic dust, metal fumes and chemicals. Thorax 2011;66:992-6.

5 Blanc PD, Annesi-Maesano I, Balmes JR, et al. The occupational burden of nonmalignant respiratory diseases. An official American Thoracic Society and European Respiratory Society statement. Am J Respir Crit Care Med 2019;199:1312-34.

6 Backhaus E, Berg S, Andersson R, et al. Epidemiology of invasive pneumococcal infections: manifestations, incidence and case fatality rate correlated to age, gender and risk factors. BMC Infect Dis 2016;16:367.

7 Torres A, Cillóniz C, Blasi F, et al. Burden of pneumococcal community-acquired pneumonia in adults across Europe: a literature review. Respir Med 2018;137:6-13.

8 Nuorti JP, Butler JC, Farley MM, et al. Cigarette smoking and invasive pneumococcal disease. N Eng/ J Med 2000;342:681-9.

9 Wong A, Marrie TJ, Garg S, et al. Welders are at increased risk for invasive pneumococcal disease. Int J Inf Dis 2010;14:e796-9.

10 Marrie TJ, Tyrrell GJ, Majumdar SR, et al. Invasive pneumococcal disease: still lots to learn and a need for standardized data collection instruments. Can Respir J 2017;2017:1-9.

11 ILO. International classification of occupations, ISCO-88. Geneva: ILO, 1990.

12 Lillienberg L, Andersson E, Janson C, Dahlman-Höglund A, et al. Occupational exposure and new-onset asthma in a population-based study in Northern Europe (RHINE). Ann Occup Hyg 2013;57:482-92.

13 Rothman KJ. Epidemiology. An introduction. New York: Oxford University Press, 2012.

14 Ludvigsson JF, Andersson E, Ekbom A, et al. External review and validation of the Swedish national inpatient register. BMC Public Health 2011;11:450.

15 Baxter R, Yee A, Aukes L, et al. Risk of underlying chronic medical conditions for invasive pneumococcal disease in adults. Vaccine 2016;34:4293-7.

16 Grau I, Ardanuy C, Calatayud L, et al. Smoking and alcohol abuse are the most preventable risk factors for invasive pneumonia and other pneumococcal infections. Int J Inf Dis 2014;25:59-64.

17 Torén K, Olin A-C, Lindberg A, et al. Vital capacity and COPD: the Swedish cardiopulmonary biolmage study (SCAPIS). Int J Chron Obstruct Pulmon Dis 2016;11:927-923.

18 Ali SM, Chaix B, Merlo J, et al. Gender differences in daily smoking prevalence in different age strata: a population-based study in southern Sweden. Scand J Public Health 2009;37:146-52.

19 Wergeland E, Iversen BG. Deaths from pneumonia after welding. Scand J Work Environ Health 2001;27.

20 Ewing J, Patterson L, Irvine N, et al. Serious pneumococcal disease outbreak in men exposed to metal fume-detection, response and future prevention through pneumococcal vaccination. Vaccine 2017;35:3945-50.

21 Flodin U, Paues J, Åkerlind B, et al. Svetsare —en riskgrupp för septisk pneumoni. vaccination kan Vara motiverat för yrkesgruppen. Läkartidningen 2017;114:225-7. [In Swedish].

22 Koh D-H, Moon K-T, Kim J-Y, et al. The risk of hospitalisation for infectious pneumonia in mineral dust exposed industries. Occup Environ Med 2011;68:116-9.

23 Palmer KT, McNeill Love RMC, McNeill-Love R, et al. Inflammatory responses to the occupational inhalation of metal fume. Eur Respir J 2006:27:366-73.

24 Ghio AJ. Particle exposures and infections. Infection 2014;42:459-67.

25 Di Benedetto F, Gazzano E, Tomatis M, et al. Physico-chemical properties of quartz from industrial manufacturing and its cytotoxic effect on alveolar macrophages. $J$ Hazard Matter 2016;312:18-27.

26 Suri R, Periselneris J, Lanone $\mathrm{S}$, et al. Exposure to welding fumes and lower airway infection with Streptococcus pneumoniae. J Allergy Clin Immunol 2016;137:527-34.

27 Kennedy SM. When is a disease occupational? Lancet 1994:344:4-5.

28 Örtqvist A, Hedlund J, Kalin M. The elderly should be vaccinated against pneumococci [In Swedish]. Läkartidningen 1999;96:1305-8.

29 Coggon D, Harris EC, Cox V, et al. Pneumococcal vaccination for welders. Thorax 2015:70:198-9. 